Proc. Indian Acad. Sci. (Earth Planet. Sci.), Vol. 95, No. 3, November 1986. pp. 311-319.

(C) Printed in India.

\title{
In situ stress measurements using hydraulic fracturing method
}

\author{
T N GOWD, S V SRIRAMA RAO, K B CHARY and F RUMMEL ${ }^{+}$ \\ National Geophysical Research Institute, Hyderabad 500007 . India \\ + Institute of Geophysics, Ruhr University Bochum, Bochum, FRG \\ MS received 11 December 1985; revised 30 May 1986
}

\begin{abstract}
The first in situ stress measurements in India were carried out in $176 \mathrm{~m}$ deep borehole by employing deep-hole wireline hydraulic fracturing equipment. The results reveal that the direction of maximum compression is oriented at $\mathrm{N} 35^{\circ} \mathrm{E}$, and the existence of high-near-surface horizontal stresses compared with the overburden pressure. This can be attributed to the continuing convergence of Indian and Eurasian plates. Earthquakes experienced near Hyderabad could be due to refracturing of some NNE or $\mathrm{NE}$ trending mineralized fractures which persistently occur in the area, as these fractures are critically oriented with respect to the present-day stress field.
\end{abstract}

Keywords. In situ stresses; hydraulic fracturing; breakdown pressure; refrac pressure; shut-in pressure; natural planes of weakness; maximum compression.

\section{Introduction}

The Indian continent is characterized by high seismicity in the Himalayas and the adjoining north-eastern region. The Himalayan region is one of the most seismically active belts of the world and has experienced several major earthquakes during historical times (Khattri et al 1984). During the past hundred years two earthquakes of magnitude 8.7 and seventeen of magnitude greater than 7.0 have occurred in north-eastern India besides innumerable minor earthquakes (Gaur 1983; Gupta et al 1984). Until recently, the Indian shield was considered as generally aseismic. However, with the improvement of the seismic network it is now recognized that widespread, although minor, seismicity exists throughout peninsular India (Indra Mohan et al 1981). During 1964-70 six earthquakes of magnitude about 6.0 occurred in widely separated locations on peninsular India (Chandra 1977). In the Hyderabad region, four minor earthquakes of magnitude not exceeding 4.5 occurred during the past 15 years (Kanungo et al 1978; Rastogi and Chadha 1984). The high seismicity in the Himalayas and north-eastern India, and the widespread minor seismicity in peninsular India can be attributed to the existence of high tectonic stresses at the collision zone which progressively diminish southwards. These stresses are caused by the continuing convergence of the Indian and Eurasian plates which over the past 40 million years have resulted in the folding and uplift of the collision zone into one of the loftiest mountain ranges of the world. A precise knowledge of the stress regime (magnitude as well as direction of the in situ stresses) prevailing in different tectonic segments of the country is essential in understanding not only the observed seismicity but also the detailed geodynamics of the region which could enable one to estimate for example the recurrence period of major earthquakes. Besides, in situ stress data find 
important applications in engineering, such as designing of underground rock structures, planning of large-scale hydraulic fracturing operations to stimulate oil and gas wells, extracting geothermal energy, disposing industrial liquid wastes into the subsurface rocks etc.

Although the importance of the knowledge of the in situ stresses has long been recognized in the country, no direct stress measurements were made so far due to lack of expertise. In order to fill this gap, capabilities have been developed at the National Geophysical Research Institute for carrying out in situ stress measurements by hydraulic fracturing in deep boreholes (upto $500 \mathrm{~m}$ deep) of 3-5 inches diameter. The first in situ stress measurements in India were carried out recently at Hyderabad in a $176 \mathrm{~m}$ deep borehole using the wireline hydraulic fracturing equipment. The methodology and the results of these first measurements are presented and discussed in this paper.

\section{Experimental technique}

\subsection{Wireline hydrofracturing system}

A schematic of the Bochum Wireline Hydrofrac System (Rummel and Baumgartner 1985) used in the tests is shown in figure 1 . The equipment comprises of double straddle packer assembly, winch and pumping unit with a heavy duty tripod, $500 \mathrm{~m}$ long 7-conductor electromechanical cable and a high pressure rubber hose mounted on a 4-wheel trailor. The equipment also includes the pressurising system and electronic data recording system.

The straddle packer assembly consists of two nylon reinforced rubber elements, an injection unit of $36 \mathrm{~cm}$ long, a push-pull valve assembly and a pressure release valve assembled on a steel mandrel. The active sealing length of the packer elements is about $1 \mathrm{~m}$, and a test interval (70-120 cm long) can be had by using injection units of suitable lengths. Packers used in the present investigation can effectively seal the test interval for injection pressures as high as 300 bars. However, special rubber packers are available for injection pressures of upto 400 bars. The wireline hydrofrac equipment includes a novel feature i.e., a push-pull valve assembly by which fluid pressure can be applied either into the packers or into the test interval using only one pressure line. The push-pull valve mounted on the straddle packer assembly is activated to connect the pressure line either to the packers or to the test interval by applying or releasing the tension in the cable respectively.

A pressure release valve, mounted on top of the push-pull valve, is connected to the packers and gaurantees fast and complete deflation of the packers. This is especially important in dry boreholes where the packers may remain partially inflated even after venting the system at the surface. The linkage between the logging cable and the packer assembly is provided by the cable head. A pressure transducer with an integrated amplifier is housed within the cable head, and measures downhole either by the packer pressure or fluid pressure in the test interval depending upon the position of the push-pull valve.

The winch and the pumping system, mounted on a 4-wheel trailor are driven by a $22 \mathrm{~kW}$ diesel engine and a hydraulic pump (figure 2). The winch drum is integrated 


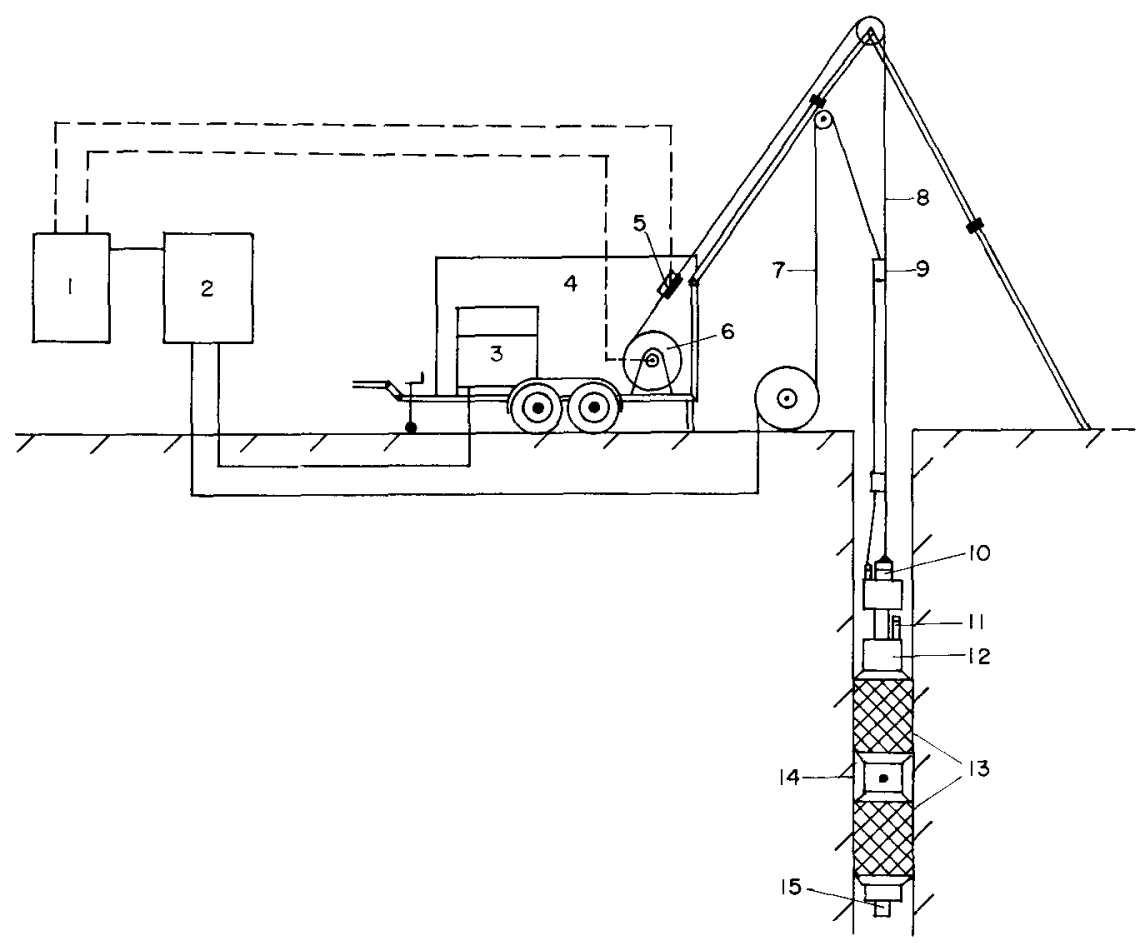

Figure 1. Schematic diagram of the Bochum wireline hydrofrac system. 1. Electronic recording system 2. Pressure and flow control pancl 3. Pumping unit 4. Trailor mounted winch and pumping unit 5. Rotational transducer to indicate depth 6. Cable drum 7. High pressure hose 8. Seven conductor logging cable 9. Clamp to connect hose to cable 10. Pressure transducer 11. Release valve 12. Push-pull valve 13. Packer elements 14. Fracture interval 15. Steel mandrel over which the hydrofrac tool $(10-13)$ is assembled.

with hydraulic motors and a brake. The pulling capacity of the winch is set to 20 kilo Newtons (KN), but can be tuned to $40 \mathrm{KN}$. The system incorporates automatic cable wind-up, and an electronic depth monitoring device. Cable tripping speed can be varied upto about $0.8 \mathrm{~m} / \mathrm{sec}$. The pumping system consists of a hydraulic motor and a duplex plunger pump and provides a maximum pumping rate of $10 \mathrm{l} / \mathrm{min}$ at pressures of upto 500 bars. Winch and pump operations are remote controlled. The packer assembly is tripped to depth by a heavy-duty aluminium tripod. Strike and dip of the hydrofractures induced in the test intervals are obtained by using an impression packer assembly in conjunction with a single shot borehole orientation tool.

The electronic system comprises of surface and downhole pressure transducers, a surface flow meter, strip-chart recorder and a magnetic tape recorder. Surface and downhole pressures, pumping rate and total flow are recorded on the strip-chart recorder and on the tape recorder. This allows direct data observation during a fracture test as well as for final data processing. 


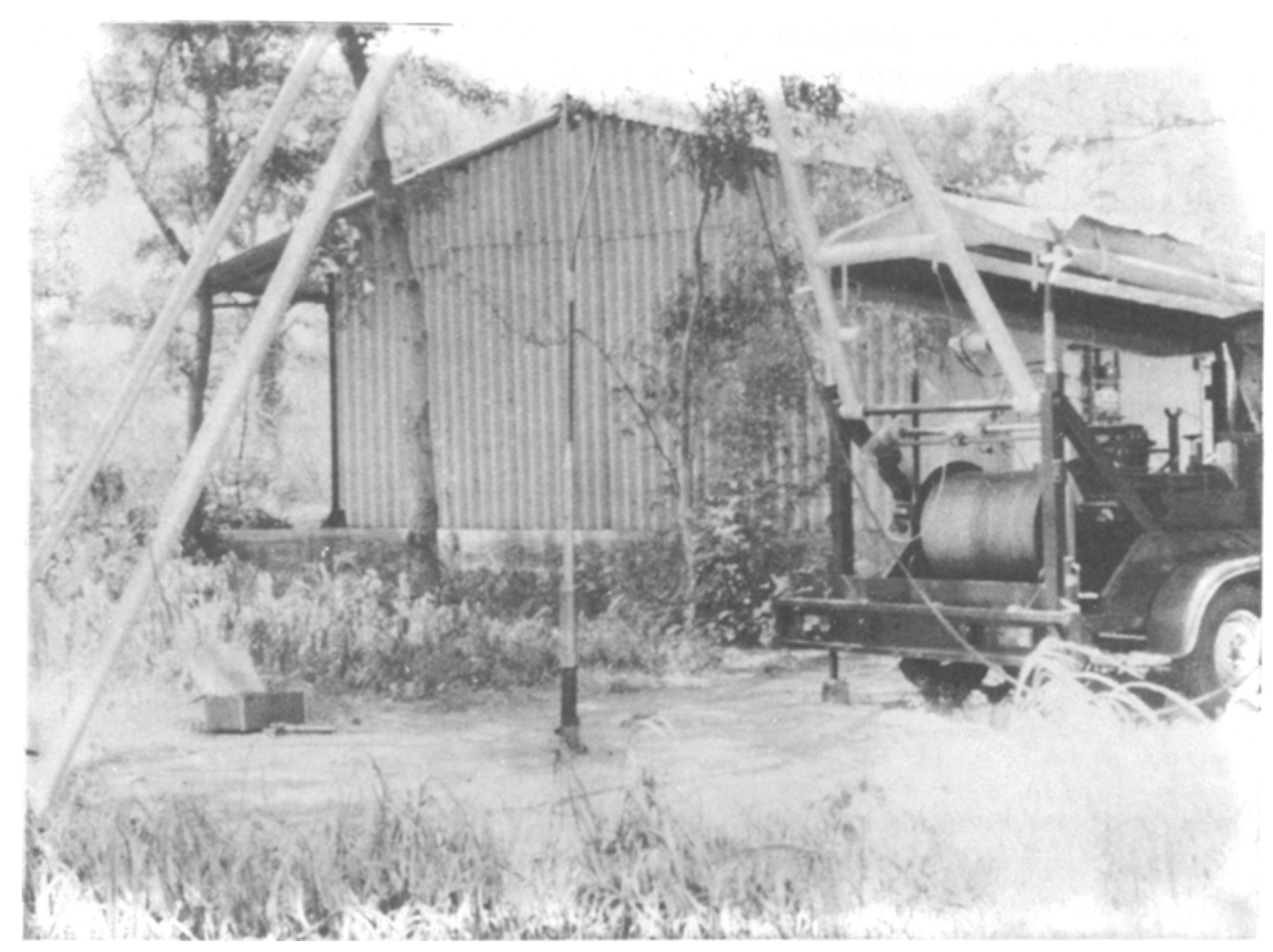

Figure 2. A view of the trailor mounted wireline hydrofrac equipment.

\subsection{Testing procedure}

Prior to conducting hydrofrac tests. the cores recovered from the borehole are critically examined to determine the nature and location of natural planes of weakness (NPW) and the fracture logs are prepared. Generally intact sections of the borehole which are free from NPW are selected for the frac tests. After the straddle packer assembly is tripped to the maximum predetermined depth and the packers are set, the test interval is instantaneously pressurized to 25 bars for determining rock permeability. Then, the fracture is induced and propagated at the full pumping rate in several phases with 10 to 20 litres of water being injected during each phase. The tests yield the hydrofrac data i.e. breakdown pressure $P_{C}$ (frac initiation), the re-opening pressure $P_{R}$ and the shut-in pressure $P_{S I}$. Shut-in pressure is also obtained from the slow-rate pumping tests. In all cases water recovered after venting is measured as a function of time for a period upto 30 minutes in some cases. This test procedure is repeated after the packer assembly is moved upwards to the next pre-determined test interval. After the completion of all the frac tests, imprint/impression of each induced fracture is obtained by the wireline impression packer unit.

\section{Geology}

The area consists essentially of one major rock formation viz pink and grey granites and forms a part of the huge granitic batholith that covers an area of about 
$5000 \mathrm{~km}^{2}$ in the Telengana Region of Andhra Pradesh. These granites are presumed to be a part of the peninsular gneissic complex of Precambrian age $(2$ billion years). The granites have, in general. a NW-SE trend of foliation which is also the regional trend of Dharwars. Two important major structural features i.e. pink alaskites striking $\mathrm{N} 30^{\circ} \mathrm{W}-\mathrm{S} 30^{\circ} \mathrm{E}$ and basic dykes trending $\mathrm{E}-\mathrm{W}$ occur in the area. Another set of structural features comprising of mineralized fractures such as aplite veins, pegmatite veins, epidote veins and quartz reefs (mentioned here in the decreasing order of their age) are found in this area. These features, particularly epidote veins and quartz reefs, exhibit consistent NE-SW trends. Two prominent sets of joints are abundantly present in the area. One set strikes in $\mathrm{N} 60^{\circ} \mathrm{W}-\mathrm{S} 60^{\circ} \mathrm{E}$ direction while the other set trends $\mathrm{N} 10^{\circ} \mathrm{E}-\mathrm{S} 10^{\circ} \mathrm{W}$. Detailed lithology and fracture logs were prepared by carefully examining the cores recovered from the borehole (Gowd et al 1985). Considering the fracture logs, twelve hydrofrac test intervals were selected in the intact zones.

\section{Results and discussion}

A typical pressure-time record of the hydrofrac test is shown in figure 3 which indicates the initiation of a fracture (frac test), propagation of the fracture (refrac test) and slow-rate pumping test at $117 \mathrm{~m}$ depth during several pressurisation tests. The values of $P_{C}, P_{R}$ and $P_{S I}$ were determined from the pressure time record. Similarly, tests were conducted at other 11 test intervals and the respective $P_{C}, P_{R}$ and $P_{S I}$ were determined. The results reveal that $P_{C}$ required to initiate fractures in intact granite (upto a depth range of $150 \mathrm{~m}$ ) range between 63 and 167 bars, re-opening pressures between 34 and 110 bars, and $P_{S I}$ just sufficient to keep the fractures open against the normal stress, range between 24 and 78 bars (table 1).

Frac impression data reveal that vertical fractures were induced at eight test intervals while pre-existing inclined fractures re-opened at the other four test locations. The strike and dip of these fractures are given in table 1 . The azimuth of the induced vertical fractures is presented in Fig. 4 and demonstrates that the

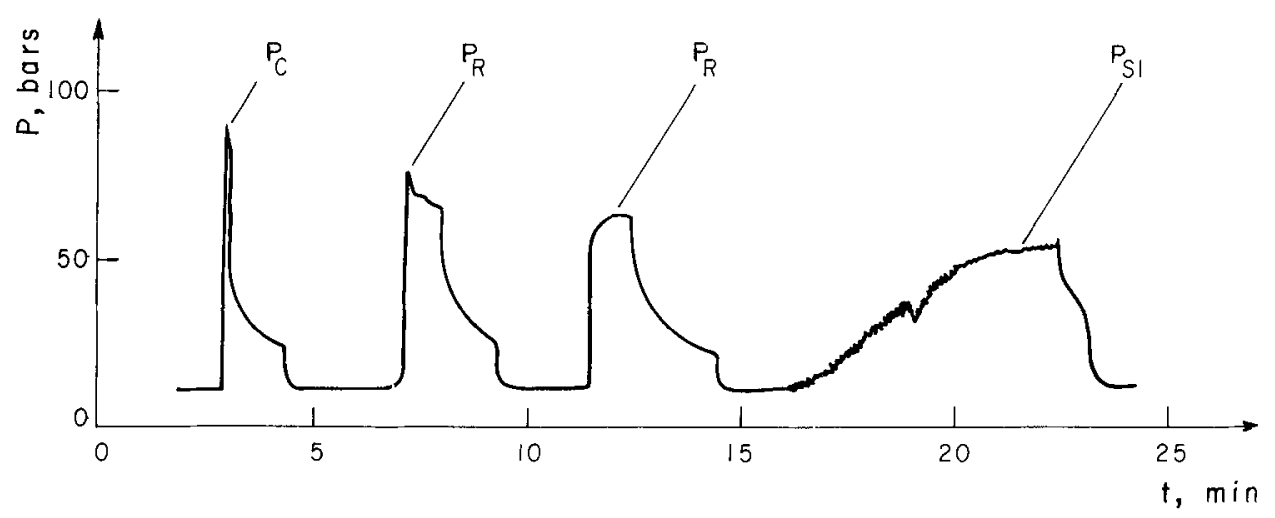

Figure 3. Pressuac-tume record of the hydrofrac tests conducted at $117.00 \mathrm{~m}$ depth $n$ the NGRI campus borehole. Hyderabad. 
Table 1. Frac data obtamed in the N.G.R.I. campus borehole, Hyderabad.

\begin{tabular}{|c|c|c|c|c|c|c|c|}
\hline $\begin{array}{l}\text { Test } \\
\text { No. }\end{array}$ & $\begin{array}{c}\text { Depth } \\
\text { (m) }\end{array}$ & $\begin{array}{c}P_{r} \\
\text { (bars) }\end{array}$ & $\begin{array}{c}P_{K} \\
\text { (bars) }\end{array}$ & $\begin{array}{c}P_{S I} \\
\text { (bars) }\end{array}$ & $\begin{array}{c}T \\
\text { (bars) }\end{array}$ & $\begin{array}{c}\text { Frac } \\
\alpha^{\circ}\end{array}$ & $\begin{array}{c}\text { Orientation } \\
d^{\circ}\end{array}$ \\
\hline H. 1 & 43.80 & 90 & 34 & 24 & 56 & 56 & 62 \\
\hline H. 2 & $46 \cdot 75$ & 79 & 48 & 36 & 31 & 345 & 14 \\
\hline H. 3 & $50 \cdot 00$ & 94 & 76 & 45 & 18 & 35 & $90(\mathrm{~V})$ \\
\hline H. 4 & $66 \cdot 00$ & 66 & 53 & 40 & 13 & 33 & $90(\mathrm{~V})$ \\
\hline H. 5 & $72 \cdot 75$ & 81 & 63 & 45 & 18 & 50 & $90(\mathrm{~V})$ \\
\hline H. 6 & $76 \cdot 00$ & 63 & 52 & 30 & 11 & 351 & 52 \\
\hline H. 7 & 96.00 & 126 & 87 & 57 & 39 & 37 & $90(\mathrm{~V})$ \\
\hline H. 8 & $107 \cdot 75$ & 119 & 81 & 57 & 38 & 55 & $90(\mathrm{~V})$ \\
\hline H. 9 & $111 \cdot 40$ & 85 & 76 & 57 & 9 & 39 & 36 \\
\hline H. 10 & $117 \cdot 00$ & 88 & 62 & 53 & 26 & 19 & $90(\mathrm{~V})$ \\
\hline H. 11 & $139 \cdot 44$ & 123 & 71 & 56 & 52 & 52 & $90(\mathrm{~V})$ \\
\hline H. 12 & $149 \cdot 00$ & 167 & 110 & 78 & 57 & 40 & $90(\mathrm{~V})$ \\
\hline
\end{tabular}

$P_{C}$ : Breakdown pressure; $P_{R}$ : Refrac pressure; $P_{S I}$ : Shut-in pressure; $T$ : in situ tensile strength $\left(P_{C}-P_{R}\right) ; \alpha$ : Orientation of frac plane (measured eastward from the north); $d$ : dip of frac plane with respect to the horizontal.

induced vertical fractures are consistently oriented in NE-SW quadrant throughout the $50-150 \mathrm{~m}$ depth section investigated, average of all these eight orientations being $\mathrm{N} 40^{\circ} \pm 13^{\circ} \mathrm{E}$.

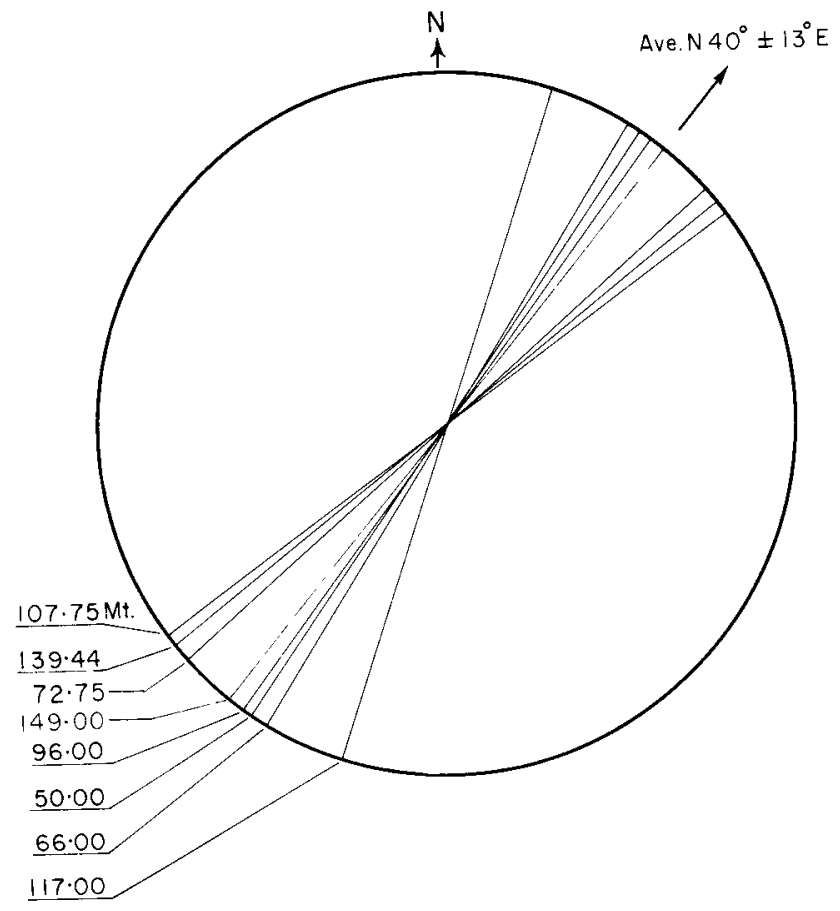

Figure 4. Orientation of the vertical fractures induced durme the hydrofrac tests at various depths in the NGRI campus borchole. Hyderabid 
The procedure followed to derive stress data from hydraulic fracturing pressure records is the same as that used by other hydrofrac groups (Rummel et al 1983; Haimson and Lee 1984). First, the magnitude of the principal horizontal stresses was computed from the hydrofrac data using the classical interpretation method (Hubbert and Willis 1957) which is based on the assumption that the strike of the induced vertical fractures coincides with the direction of the maximum horizontal principal stress. The following reactions were used in this classical approach.

$$
\begin{aligned}
& S_{h}=P_{S I} \\
& S_{H}=3 P_{S I}-P_{R}-P_{O},
\end{aligned}
$$

where $S_{H}$ and $S_{h}$ are the maximum and minimum principal horizontal stresses respectively and $P_{O}$ is the pore fluid pressure. The values of $S_{H 1}$ and $S_{h}$ are evaluated and the same are plotted as a function of depth in figure 5 (circles). The best straight line fits (broken lines) to the data points are also shown in the figure.

The principal stresses were also computed from the shut-in pressure data only using the computer method developed by Cornet and Valette (1984), and Baumgartner et al (1986). This non-classical i.e. $P_{S /}$ method allows one to consider the pressure data of the inclined fracture also. The results reveal that the principal horizontal stresses vary with depth as per the following equations

$$
\begin{aligned}
& S_{H} \text { (bars) }=27+0.45 Z \text { (meters), } \\
& S_{h} \text { (bars) }=26+0.25 Z \text { (meters). }
\end{aligned}
$$

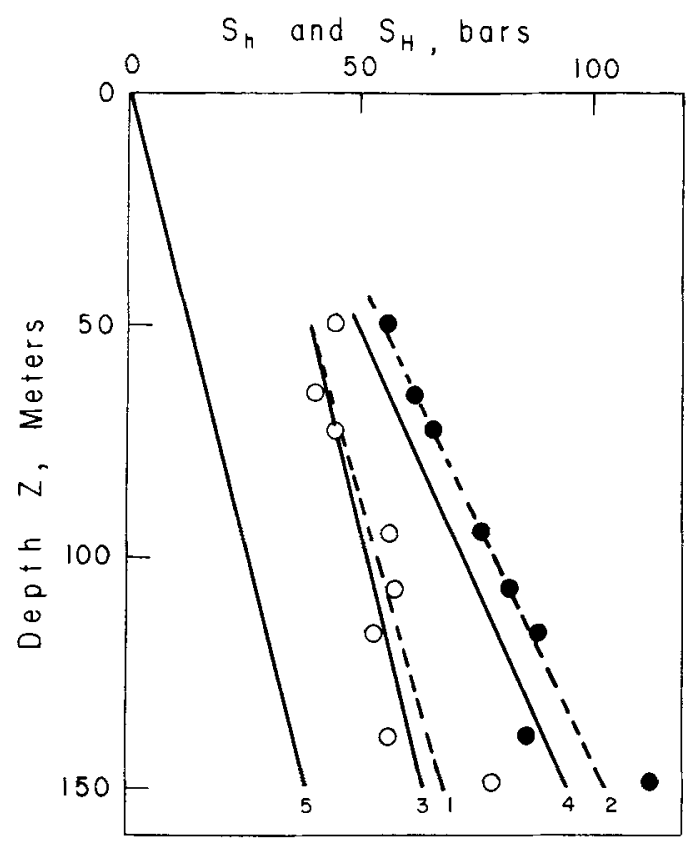

Figure 5. Maximum and munimum principal horizontal stresses $\left(S_{1 /}, S_{h_{1}}\right)$ as a function of depth of Hyderabad; $(0, \bullet): S_{h l} S_{H}$, values computed using the classical interpretation method, $(1,2)$ : Best straight line fits to data points $(0, \bullet),(3,4): S_{H}, S_{H}$ values computed using the $P_{S I}$ method, (5): Overburden pressure. 
The plots of $S_{H}$ and $S_{h}$ are also shown in figure 5 (continuous lines). These equations reveal that the maximum and minimum principal horizontal stresses are about 72 bars and 51 bars at $100 \mathrm{~m}$ depth, and about 117 bars and 76 bars at $200 \mathrm{~m}$ depth respectively, whereas the vertical stress (overburden pressure) is about 26 bars and 52 bars only at these depths. Thus the results demonstrate the existence of high near-surface horizontal stresses compared with the overburden pressure, indicating that they are of tectonic origin.

The computations based on the $P_{S I}$ method have also yielded the direction of the maximum principal horizontal stress as $N 35^{\circ} \mathrm{E}$, which closely agrees with the average azimuth of the induced vertical fractures $\left(\mathrm{N} 40^{\circ} \pm 13^{\circ} \mathrm{E}\right)$. First motion data of the earthquakes that occurred recently near Hyderabad also indicates the existence of horizontal compression in the northeast direction (Kanungo et al 1978). The observed direction of the maximum horizontal compression is in agreement with the general understanding of the north-eastward motion of the Indian continent. This suggests that the collision of the Indian continent with the Eurasian plate 40 million years ago not only resulted in the folding and the uplift of the collision zone into one of the loftiest mountain ranges of the world i.e. the Himalayas but was also responsible for inducing high intraplate stresses in the Indian shield as far south as Hyderabad. However, this statement needs to be confirmed by further measurements in different parts of the Indian shield.

Mineralized fractures such as epidote veins, quartz reefs etc predominently strike in the northeast quadrant in the Hyderabad region (Sitaramayya 1969; Kanungo

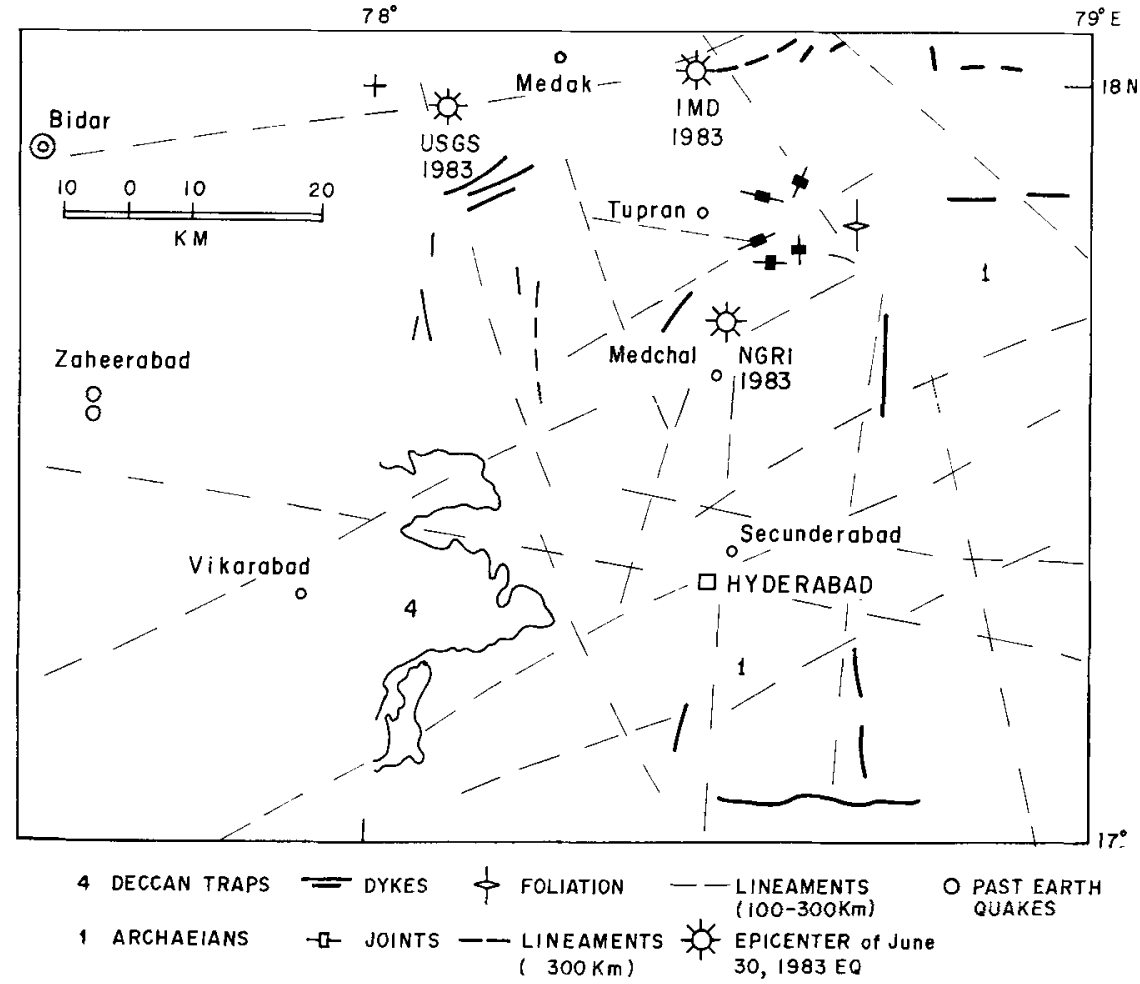

Figure 6. Mega-lineament map of Hyderabad area. 
et al 1975). Mega-lineament map of the Hyderabad area (figure 6) also shows strong trends in the NNE and NE directions. It appears that the intraplate stresses in the area whose magnitude at depth can be gauged from the observed high near surface stresses, are sufficient to cause time-dependent deformations, which, over a period of $50-100$ years will result in the accumulation of strain energy that is capable of refracturing or giving rise to seismic slip along some of these pre-existing weak planes since they are most favourably oriented with respect to the present day stress field. This would also explain the recent occurrence of four minor earthquakes (magnitude $\geq 4.5$ ) in the area as well as the earthquake that occurred near Hyderabad in 1876.

\section{Acknowledgements}

The authors thank Prof. V K Gaur for valuable suggestions, encouragement and support. The wireline hydrofrac equipment used in the present investigation was received by NGRI as a gift from the KFA-Julich, West Germany under the CSIR-KFA technical co-operation agreement. Mr J Baumgartner, Ruhr University Bochum, West Germany computed the stresses. Mr Syed Ali, Mr K P C Kaladhara Rao and Mr C Prakash of the Rock Mechanics group of NGRI assisted in carrying out in situ stress measurements.

\section{References}

Baumgartner J, Rummel $\mathrm{F}$ and Chu Zhaotan 1986 in Falkenberg granite research project (eds) $\mathrm{O}$ Kappelmeyer and F Rummel (Hannover: BGR) (in press)

Chandra U 1977 Bull. Seism. Soc. Am. 671387

Cornet F H and Valette B 1984 J. Geol. Res. 8911527

Gaur V K 1983 in Rock mechanics (eds) T N Gowd and F Rummel (Hyderabad) Proc. Indo-German Workshop on Rock Mechanics p. 97

Gowd T N, Srirama Rao S V and Çhary K B 1985 NGRI Technical Report (unpublished)

Gupta H K, Singh S C, Dutta T K and Saikia MM 1984 in A collection of papers of Int. Symp. on continental seismicity and earthquake prediction (Beijing China: Seismological Press) p. 63

Haimson B C and Lee M Y 1984 in Proc. 25th U S Symp. on Rock Mechanics (Evanston) AIME p. 194

Hubbert M K and Willis D G 1957 Petro. Trans. AIME 210153

Indra Mohan, Sitaram M V D and Gupta H K 1981 J. Geol. Soc. India 22292

Kanungo D N, Rama Rao P, Murthy D S N and Ramana Rao A V 1975 Geophys. Res. Bull. 13337

Kanungo D N, Indra Mohan, Rama Rao P and Murthy D S N 1978 Indian J. Earth Sci. 5169

Khattri K N, Rogers A M, Perkins D M and Algermissen S T 1984 Tectonophysics 10893

Rastogi B K and Chadha R K 1984 Proc. Symp. Earthquake effects on plant and equipment p. 33 R \& D Branch, BHEL, Hyderabad

Rummel F, Baumgartner $J$ and Alheid 1983 in Hydraulic fracturing stress measurements Washington Natl. Acad. Sci. p. 3

Rummel F and Baumgartner J 1985 N. Jb. Geol. Palaont. Abh. 171183

Sitaramayya S 1969 J. Indian Geosci. Assn. 11161 